\title{
Taxonomic study of neutrotolerant acidophilic actinomycetes isolated from soil and description of Streptomyces yeochonensis sp. nov.
}

Correspondence Seung Bum Kim sbk01@kribb.re.kr

\author{
Seung Bum Kim, ${ }^{1,2}$ Chi Nam Seong, ${ }^{3}$ Soo Jin Jeon, ${ }^{3}$ Kyung Sook Bae \\ and Michael Goodfellow ${ }^{2}$ \\ ${ }^{1}$ Korean Collection for Type Cultures, Korea Research Institute of Bioscience and \\ Biotechnology, 52 Oun Dong, Yusong, Daejon 305-333, Republic of Korea \\ ${ }^{2}$ School of Biology, University of Newcastle, Newcastle upon Tyne NE1 7RU, UK \\ ${ }^{3}$ Division of Biological Sciences, College of Natural Sciences, Sunchon National University, \\ Sunchon 540-742, Republic of Korea
}

\begin{abstract}
Acidophilic actinomycete strains that represent the two major neutrotolerant clusters defined by numerical taxonomy (Seong, 1992) were the subject of a polyphasic taxonomic study. The centrotypes of each cluster, designated as strain JL164 (=KCTC 9924) of cluster 21 and strain CN732 ${ }^{\top}\left(=\right.$ KCTC $9926^{\top}=$ IMSNU $50114^{\top}=$ NRRL B-24245 ${ }^{\top}$ ) of cluster 13 , were assigned initially to the genus Streptomyces on the basis of morphological and chemotaxonomic characteristics; this assignation was confirmed by $16 \mathrm{~S}$ rRNA gene sequence data. Strain $\mathrm{CN} 72^{\top}$ formed a distinct phyletic line within the Streptomyces tree, whereas strain JL164 was related closely to the type strain of Streptomyces mirabilis. It is evident from the present and previous studies that neutrotolerant acidophilic actinomycetes comprise taxonomically diverse groups within the variation encompassed by the genus Streptomyces. It is also apparent that strain $\mathrm{CN} 32^{\top}$ and other members of cluster 13 merit recognition as a novel species, for which the name Streptomyces yeochonensis sp. nov. is proposed.
\end{abstract}

Acidophilic actinomycetes are common in terrestrial habitats such as acidic forest and mine drainage soils, where they are a major constituent of the actinomycete community (Williams et al., 1971; Khan \& Williams, 1975; Hagedorn, 1976; Lonsdale, 1985; Seong, 1992). Jensen (1928) described 'Actinomyces (Streptomyces) acidophilus', a taxon that harboured four acidophilic actinomycetes isolated from acidic soil; apart from this, no attempt has been made to describe such organisms formally, although representative acidophilic and neutrotolerant sporoactinomycetes have been compared with neutrophilic streptomycetes in a 5S rRNA gene analysis (Park et al., 1991). It has been shown that acidophilic actinomycetes consistently form two distinct aggregate taxa (namely, the neutrotolerant acidophilic and strictly acidophilic cluster-groups) on the basis of numerical phenetic data; members of the two groups share common morphological and chemotaxonomic properties (Khan \& Williams, 1975; Lonsdale, 1985; Seong, 1992).

Published online ahead of print on 1 August 2003 as DOI 10.1099/ ijs.0.02519-0.

The GenBank/EMBL/DDBJ accession numbers for the 16S rRNA gene sequences of strains $\mathrm{JL} 164$ and $\mathrm{CN} 732^{\top}$ are AF101414 and AF101415, respectively.
Members of each of the aggregate groups produce extensively branched vegetative mycelia and long chains of arthrospores on the tips of aerial hyphae. Whole-organism hydrolysates of representative strains have been shown to contain major amounts of LL-diaminopimelic acid, tetra-, hexa- and octahydrogenated menaquinones with nine isoprene units and type II phospholipids sensu Lechevalier et al. (1977). In contrast, members of the two groups show different $\mathrm{pH}$ ranges for growth and can be distinguished by phenotypic criteria, such as carbon utilization patterns. Neutrotolerant acidophilic actinomycetes grow at a $\mathrm{pH}$ range from 3.5 to around neutral, with optimal growth between pH 5.0 and 5.5 (Lonsdale, 1985); strictly acidophilic strains show a restricted $\mathrm{pH}$ range for growth, with optimal $\mathrm{pH}$ around $4 \cdot 5$. Members of the neutrotolerant group are less able to use a range of carbon sources than their acidophilic counterparts (Seong et al., 1993, 1995).

It has been shown that some members of the strictly acidophilic group form a distinct taxon, the genus Streptacidiphilus, which has been assigned to the revised family Streptomycetaceae, together with the genera Kitasatospora and Streptomyces (Kim et al., 2003). In contrast, members of the neutrotolerant acidophilic group have received 
relatively little attention, although there is evidence from chemotaxonomic and morphological studies that they should be assigned to the genus Streptomyces. The aim of the present study was to determine the relationships of some neutrotolerant acidophilic actinomycetes by using a polyphasic approach.

Two major neutrotolerant acidophilic taxa were defined by Seong (1992) in a numerical phenetic study: namely, clusters 13 (five members) and 21 (nine members). Cluster 13 , represented by the centrotype strain $\mathrm{CN}^{1} 32^{\mathrm{T}}(=\mathrm{KCTC}$ $\left.9926^{\mathrm{T}}=\mathrm{IMSNU} \quad 50114^{\mathrm{T}}=\mathrm{NRRL} \quad \mathrm{B}-24245^{\mathrm{T}}\right)$, contained organisms that were isolated from different horizons of soil from a Pinus thunbergii forest, Dolsan Island, Yeochon, Republic of Korea, and cluster 21, represented by the centrotype strain JL164 (=KCTC 9924), accommodated strains that were isolated from different horizons of podsol soil at Hamsterley Forest, County Durham, UK (National Grid reference NY08337). The tested strains were maintained on acidified MBA plates (Lonsdale, 1985; Seong, 1992).

Biochemical and physiological properties of the strains were examined by using procedures described by Seong (1992). Biomass for chemotaxonomic and molecular studies was prepared as described previously (Kim et al., 2003). DNA extraction, PCR and sequencing of the $16 \mathrm{~S}$ rRNA genes of the two representative strains were also carried out by using established methods (Kim et al., 1998). The resultant sequence data were aligned with those of members of representative Streptomyces species by using CLUSTAL X version 3.1 (Thompson et al., 1997) and the alignment was checked manually. Evolutionary trees were constructed by using the least-squares (Fitch \& Margoliash, 1967), maximum-parsimony (Kluge \& Farris, 1969) and neighbour-joining (Saitou \& Nei, 1987) algorithms and phylogenetic distances were calculated after Jukes \& Cantor (1969). The topology of the phylogenetic trees was tested by bootstrap analysis (Felsenstein, 1985) of the neighbour-joining data, using the SEQBOOT and CONSENSE programs from the PHYLIP suite (Felsenstein, 1993).

The tested strains formed extensively branched substrate mycelia, chains of arthrospores that were borne on the tips of aerial hyphae and a grey aerial spore-mass. Strain JL164 formed spiral chains of spores and strain $\mathrm{CN} 732^{\mathrm{T}}$ formed straight to flexuous spore-chains. Each of the organisms contained major amounts of LL-diaminopimelic acid in whole-organism hydrolysates, and either hexa- or octahydrogenated menaquinones with nine isoprene units $\left[\mathrm{MK}-9(\mathrm{H})_{6}-9(\mathrm{H})_{8}\right]$ as predominant isoprenologues. Chemotaxonomic and morphological properties of the strains were consistent with their classification in the genus Streptomyces (Williams et al., 1989; Manfio et al., 1995). This conclusion is in good agreement with an earlier study, where acidophilic and neutrotolerant actinomycetes clustered together with other streptomycetes on the basis of 5S rRNA sequence data (Park et al., 1991).
Strain JL164 is related closely to the type strain of Streptomyces mirabilis. The two organisms share $99.6 \% 16 \mathrm{~S}$ rRNA gene sequence similarity, a value that corresponds to five nucleotide differences. Strain JL164 also showed a relatively close affinity with Streptomyces griseochromogenes DSM $40499^{\mathrm{T}}$, Streptomyces pseudovenezuelae NRRL-ISP $5212^{\mathrm{T}}$ and Streptomyces resistomycificus DSM $40133^{\mathrm{T}}$; it shared $98 \cdot 1 \%$ 16S rRNA gene sequence similarity with these isolates, a value that equates to 26 nucleotide differences. The relationship between strain JL164 and S. mirabilis ATCC $27447^{\mathrm{T}}$ was underpinned by the results from all of the treeing algorithms and by a high bootstrap value (Fig. 1). The close relationship between the two organisms was also supported by morphological and physiological properties, notably by the fact that each of the strains produces a grey aerial spore-mass, spiral chains of spores and brown soluble pigments (Shirling \& Gottlieb, 1972; Lonsdale, 1985; Seong, 1992). S. mirabilis ATCC $27447^{\mathrm{T}}$ has been reported not to grow at $\mathrm{pH} 4 \cdot 3$ (Williams et al., 1983), but this observation must be checked, as acidophilic strains tend to grow after a relatively long lag period or even fail to grow on agar plates when glycerol stocks are used as inocula.

Strain $\mathrm{CN} 732^{\mathrm{T}}$ was related most closely to Streptomyces griseocarneus DSM $40004^{\mathrm{T}}(97 \cdot 2 \%, 39$ nucleotide differences) and Streptomyces malaysiensis ATB- $11^{\mathrm{T}}(97 \cdot 1 \%, 40$ nucleotide differences) on the basis of $16 \mathrm{~S}$ rRNA gene sequence data. However, it is clear from Fig. 1 that this organism forms an independent phyletic line in the Streptomyces $16 \mathrm{~S}$ rRNA gene tree. A $16 \mathrm{~S}$ rRNA gene similarity value of $97 \cdot 1 \%$ between strain $\mathrm{CN} 732^{\mathrm{T}}$ and $S$. griseocarneus DSM $40004^{\mathrm{T}}$, the most closely related organism, is very low when compared to the mean intrageneric similarity value of $97 \%$ that is found between representatives of Streptomyces species; also, the relationship between these two organisms is not supported by a high bootstrap value. The two organisms can also be distinguished readily on the basis of morphological properties: S. griseocarneus DSM $40004^{\mathrm{T}}$ forms a reddish aerial spore-mass and produces spores in verticils. In a comparison of 16S rRNA gene sequences using a BLAST search (Altschul et al., 1990), strain $\mathrm{CN} 732^{\mathrm{T}}$ was again found to be associated most closely with the type strain of S. griseocarneus, thereby confirming that there was no closer neighbour for which a 16S rRNA gene sequence is available in public databases. It is also interesting that strain $\mathrm{CN} 732^{\mathrm{T}}$ shares $184 / 229$ unit characters in common with the other members of cluster 13, namely strains CN718 (=IMSNU 50115), CN725 (=IMSNU 50128), CN727 (=IMSNU 50153) and CN731 (=IMSNU 50140), with mean similarity of $91 \%$ (Seong, 1992).

It is evident from this and earlier studies (Lonsdale, 1985; Seong, 1992) that strain $\mathrm{CN} 732^{\mathrm{T}}$ and other members of cluster 13 form a novel species within the genus Streptomyces, for which the name Streptomyces yeochonensis sp. nov. is proposed. 


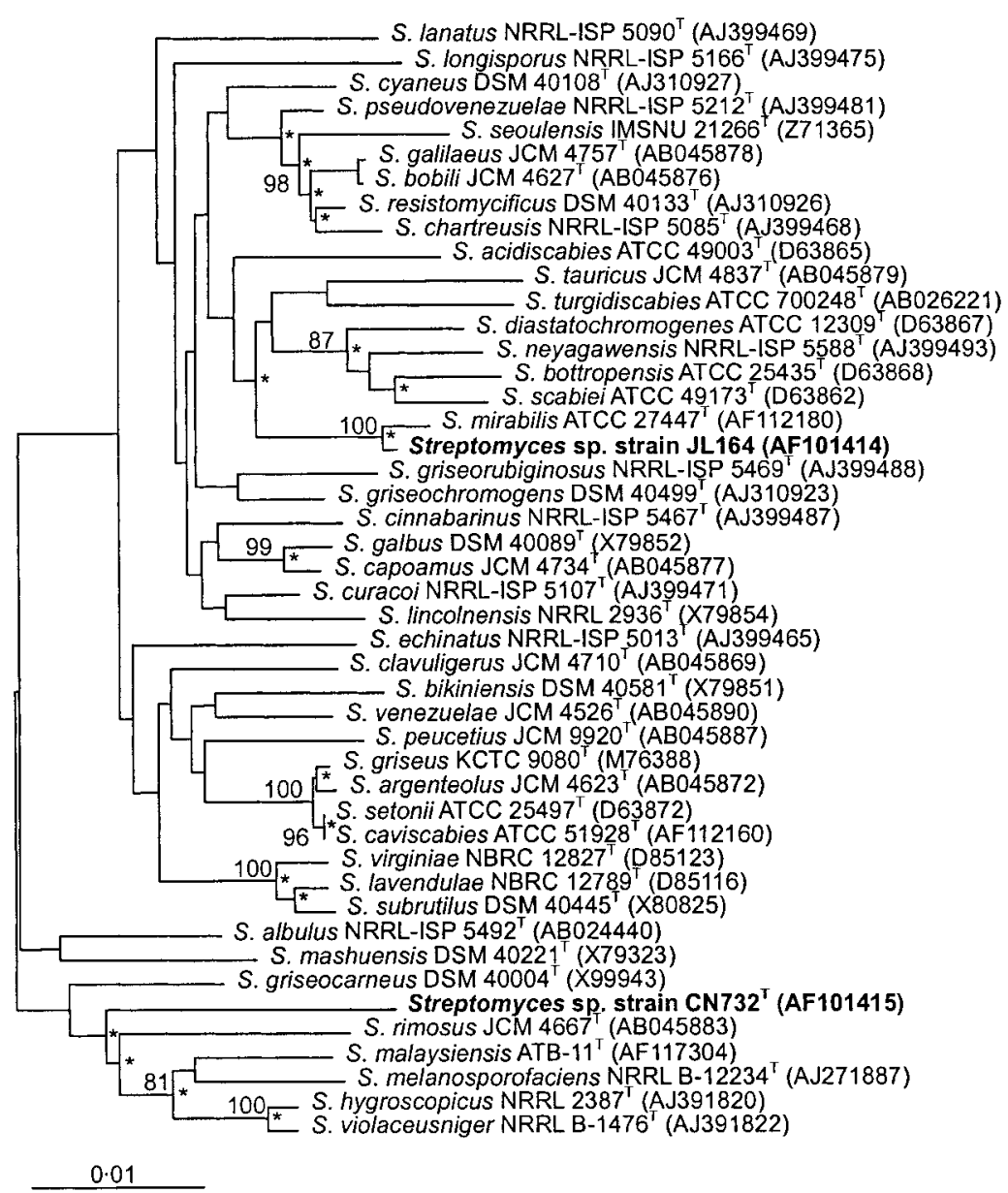

Fig. 1. Neighbour-joining tree based on almost-complete 16S rRNA gene sequences, showing relationships of strains JL164 and $\mathrm{CN}_{3} 2^{\top}$ with representative species of the genus Streptomyces. Numbers at nodes indicate bootstrap values (\%) based on 1000 resamplings; only values $>70 \%$ are shown. Asterisks indicate branches that were also recovered by the least-squares and maximum-parsimony algorithms. Bar, 0.01 substitutions per nucleotide position.

\section{Description of Streptomyces yeochonensis sp. nov.}

Streptomyces yeochonensis (ye.o.chon.en'sis. N.L. masc. adj. yeochonensis of Yeochon, a province in Korea, referring to the place where the organism was first isolated).

The description is based on the present and previous studies (Lonsdale, 1985; Seong, 1992). Aerobic, Grampositive, non-motile, neutrotolerant acidophilic streptomycete that forms extensively branched substrate and aerial mycelia. Smooth-surfaced spores are borne in flexuous spore-chains. Aerial spore-mass colour is grey. Substrate mycelia have no distinctive colour; diffusible pigments are not produced. $\mathrm{pH}$ range for growth is $4 \cdot 3-7 \cdot 3$. Casein, gelatin, guanine, starch and Tween 80 are degraded, but elastin, hypoxanthine, testosterone, Tween 20, tyrosine and xanthine are not. Good growth occurs between 25 and $37^{\circ} \mathrm{C}$, but not at 12 or $45^{\circ} \mathrm{C}$. The sugars erythritol, inulin, melezitose, salicin, ribitol and sorbitol (all at $1 \%$, w/v) are used as sole carbon sources, as are $\beta$-hydroxybutyric acid, D-gluconic acid, hippuric acid, $\alpha$-ketoglutaric acid, 2-ketoD-glucuronic acid, lactic acid, malic acid, malonic acid, oxalic acid, pyruvic acid and succinic acid (as sodium salts), albeit at $0 \cdot 1 \%, \mathrm{w} / \mathrm{v}$.

The type strain, CN732 ${ }^{\mathrm{T}}\left(=\right.$ KCTC $9926^{\mathrm{T}}=\mathrm{IMSNU} 50114^{\mathrm{T}}$
$=$ NRRL B- $24245^{\mathrm{T}}$ ), was isolated from acidic soil collected in the Yeochon area of the Republic of Korea.

The results of this and earlier studies (Lonsdale, 1985; Park et al., 1991; Seong, 1992) indicate that neutrotolerant sporoactinomycetes form a heterogeneous group of actinomycetes that belong to the genus Streptomyces, thereby underpinning the physiological diversity encompassed by this taxon (Williams et al., 1989). It is also evident that neutrotolerant streptomycetes can be distinguished readily from their acidophilic counterparts, which are classified in the genus Streptacidiphilus (Kim et al., 2003). It is clear that further comparative taxonomic studies are needed to formally describe the range of taxonomic variation encompassed by neutrotolerant streptomycetes.

\section{Acknowledgements}

This work was partly supported by KCTC grant KBM1000212. S. B. K. was supported by a Chevening-MOST fellowship awarded by the British Council (Seoul, Korea).

\section{References}

Altschul, S. F., Gish, W., Miller, W., Myers, E. W. \& Lipman, D. J. (1990). Basic local alignment search tool. J Mol Biol 215, 403-410. 
Felsenstein, J. (1985). Confidence limits on phylogenies: an approach using the bootstrap. Evolution 39, 783-791.

Felsenstein, J. (1993). PHYLIP (phylogeny inference package), version 3.5c. Department of Genetics, University of Washington, Seattle, USA.

Fitch, W. M. \& Margoliash, E. (1967). Construction of phylogenetic trees. Science 155, 279-284.

Hagedorn, C. (1976). Influences of soil acidity on Streptomyces populations inhabiting forest soils. Appl Environ Microbiol 32, 368-375.

Jensen, H. L. (1928). Actinomyces acidophilus n. sp. - a group of acidophilous actinomycetes isolated from the soil. Soil Sci 25, 225-236.

Jukes, T. H. \& Cantor, C. R. (1969). Evolution of protein molecules. In Mammalian Protein Metabolism, pp. 21-132. Edited by H. N. Munro. New York: Academic Press.

Khan, M. R. \& Williams, S. T. (1975). Studies on the ecology of actinomycetes in soil. VIII. Distribution and characteristics of acidophilic actinomycetes. Soil Biol Biochem 7, 345-348.

Kim, S. B., Falconer, C., Williams, E. \& Goodfellow, M. (1998). Streptomyces thermocarboxydovorans sp. nov. and Streptomyces thermocarboxydus sp. nov., two moderately thermophilic carboxydotrophic species from soil. Int J Syst Bacteriol 48, 59-68.

Kim, S. B., Lonsdale, J., Seong, C.-N. \& Goodfellow, M. (2003). Streptacidiphilus gen. nov., acidophilic actinomycetes with wall chemotype 1 and emendation of the family Streptomycetaceae (Waksman and Henrici $1943^{\mathrm{AL}}$ ) emend. Rainey et al. 1997. Antonie van Leeuwenhoek 83, 107-116.

Kluge, A. G. \& Farris, F. S. (1969). Quantitative phyletics and the evolution of anurans. Syst Zool 18, 1-32.

Lechevalier, M. P., De Bièvre, C. \& Lechevalier, H. A. (1977). Chemotaxonomy of aerobic actinomycetes: phospholipid composition. Biochem Syst Ecol 5, 249-260.

Lonsdale, J. T. (1985). Aspects of the biology of acidophilic actinomycetes. $\mathrm{PhD}$ thesis, University of Newcastle, Newcastle upon Tyne, UK.

Manfio, G. P., Zakrzewska-Czerwinska, J., Atalan, E. \& Goodfellow, M. (1995). Towards minimal standards for the description of Streptomyces species. Biotekhnologia 7-8, 242-253.
Park, Y.-H., Yim, D.-G., Kim, E., Kho, Y.-H., Mheen, T.-I., Lonsdale, J. \& Goodfellow, M. (1991). Classification of acidophilic, neutrotolerant and neutrophilic streptomycetes by nucleotide sequencing of 5S ribosomal RNA. J Gen Microbiol 137, 2265-2269.

Saitou, N. \& Nei, M. (1987). The neighbor-joining method: a new method for reconstructing phylogenetic trees. Mol Biol Evol 4, 406-425.

Seong, C.-N. (1992). Numerical taxonomy of acidophilic and neutrotolerant actinomycetes isolated from acid soil in Korea. $\mathrm{PhD}$ thesis, Seoul National University, Seoul, Republic of Korea.

Seong, C.-N., Goodfellow, M., Ward, A. C. \& Hah, Y. C. (1993). Numerical classification of acidophilic actinomycetes from acid soil. Kor J Microbiol 31, 355-363.

Seong, C. N., Park, S. K., Goodfellow, M., Kim, S. B. \& Hah, Y. C. (1995). Construction of probability identification matrix and selective medium for acidophilic actinomycetes using numerical classification data. J Microbiol 33, 95-102.

Shirling, E. B. \& Gottlieb, D. (1972). Cooperative description of type strains of Streptomyces. V. Additional descriptions. Int J Syst Bacteriol 22, 265-394.

Thompson, J. D., Gibson, T. J., Plewniak, F., Jeanmougin, F. \& Higgins, D. G. (1997). The CLUSTAL_X windows interface: flexible strategies for multiple sequence alignment aided by quality analysis tools. Nucleic Acids Res 25, 4876-4882.

Williams, S. T., Davies, F. L., Mayfield, C. I. \& Khan, M. R. (1971). Studies on the ecology of actinomycetes in soil. II. The $\mathrm{pH}$ requirements of streptomycetes from two acid soils. Soil Biol Biochem 3, 187-195.

Williams, S. T., Goodfellow, M., Alderson, G., Wellington, E. M. H., Sneath, P. H. A. \& Sackin, M. J. (1983). Numerical classification of Streptomyces and related genera. J Gen Microbiol 129, 1743-1813.

Williams, S. T., Goodfellow, M. \& Alderson, G. (1989). Genus Streptomyces Waksman and Henrici 1943, 339 AL . In Bergey's Manual of Systematic Bacteriology, vol. 4, pp. 2452 - 2492. Edited by S. T. Williams, M. E. Sharpe \& J. G. Holt. Baltimore: Williams \& Wilkins. 